The University of Maine

DigitalCommons@UMaine

Psychology Faculty Scholarship

Psychology

$11-2009$

\title{
A Functionalist Perspective on Social Anxiety and Avoidant Personality Disorder
}

Peter J. LaFreniere

University of Maine - Main, peter_lafreniere@umit.maine.edu

Follow this and additional works at: https://digitalcommons.library.umaine.edu/psy_facpub

Part of the Psychology Commons

\section{Repository Citation}

LaFreniere, Peter J., "A Functionalist Perspective on Social Anxiety and Avoidant Personality Disorder" (2009). Psychology Faculty Scholarship. 3.

https://digitalcommons.library.umaine.edu/psy_facpub/3

This Article is brought to you for free and open access by DigitalCommons@UMaine. It has been accepted for inclusion in Psychology Faculty Scholarship by an authorized administrator of DigitalCommons@UMaine. For more information, please contact um.library.technical.services@maine.edu. 


\title{
A functionalist perspective on social anxiety and avoidant personality disorder
}

\author{
PETER LAFRENIERE \\ University of Maine
}

\begin{abstract}
A developmental-evolutionary perspective is used to synthesize basic research from the neurosciences, ethology, genetics, and developmental psychology into a unified framework for understanding the nature and origins of social anxiety and avoidant personality disorder. Evidence is presented that social anxiety disorder (social phobia) and avoidant personality disorder may be alternate conceptualizations of the same disorder because they have virtually the same symptoms and genetic basis, and respond to the same pharmacologic and psychotherapeutic interventions. A functionalist perspective on social anxiety is formulated to (a) explain the origins of normative states of anxiety, (b) outline developmental pathways in the transition from normative anxiety to social anxiety and avoidant personality disorders, and (c) account for the processes leading to gender-differentiated patterns of anxiety-related disorders after puberty.
\end{abstract}

The use of the diagnostic criteria of the Diagnostic and Statistical Manual of Mental Disorders-Fourth Edition, Text Revision (DSM-IVTR; American Psychiatric Association, 2000) to differentiate specific psychiatric disorders and estimate their prevalence rates has been increasingly called into question by scholars advocating a revision of psychiatric theory and nosology rooted in both evolutionary and developmental perspectives that take into account individual adaptation across the lifespan (Jensen \& Hoagwood, 1997; McQuire \& Troisi, 1998; Nesse, 2000, 2005; Richters \& Cicchetti, 1993; Sroufe, 1997, 2007; Troisi, 2008; Wakefield, 1997, 2005). Two serious problems with the current system are the implausibly high prevalence rates for many types of disorders, and an excessive degree of comorbidity, both of which may stem from an overreliance on superficial symptomatology in the diagnostic process. In this essay I examine both problems with respect to various types of childhood emotional and behav-

Address correspondence and reprint requests to: Peter LaFreniere, Department of Psychology, University of Maine, Orono, ME 04469; E-mail: peter.lafreniere@umit. maine.edu. ioral problems that involve anxiety and social withdrawal, and adult social phobia (SP) and avoidant personality disorders (APDs).

I have chosen to focus my remarks on the problem of social anxiety because of the sheer magnitude of the number of cases of anxiety-related disorders being diagnosed annually in the United States at all ages, including children and adolescents. As an alternative to the medical model implicit in the DSM-IV-TR, I present a functionalist perspective designed to explain the origins of normative and pathological states of anxiety, integrating both genetic and contextual factors, as well as prior developmental history. Such a perspective must also address developmental pathways that account for the transition from normative anxiety to pathology, including lawful relations between anxiety and mood disorders like depression and related personality disorders. Finally, it must account for the processes leading to a gender-differentiated pattern of disorders wherever such a pattern exists. I begin by briefly reviewing data on prevalence and comorbidity of anxiety related disorders.

Currently, about $50 \%$ of Americans adults will be diagnosed with a psychiatric disorder during their lifetime (Kessler, Chiu, Demler, 
\& Walters, 2005). When applied to the 2004 US Census residential population estimate for ages 18 and older, this figure translates to over 115 million American adults (US Census Bureau, 2005). Of all the major mental health disorders, anxiety disorders are the most prevalent. Estimates of 1-year prevalence of anxiety disorders combining data from the Epidemiological Catchment Area study and the National Comorbidity Survey (NCS) put the prevalence at 16.4\% (Kessler et al., 1994). Moreover, data from the NCS indicates that anxiety disorders are more chronic than either mood disorders or substance abuse disorders (Kessler et al., 1994). Given these data on prevalence and chronicity, anxiety disorders are associated with substantial costs, accounting for approximately $30 \%$ of total costs of mental health care, compared to $22 \%$ for mood disorders and $20 \%$ for schizophrenia (Rice \& Miller, 1993). DuPont et al. (1996) estimated these costs in 1990 at $\$ 46.6$ billion out of a total expenditure on mental illness of $\$ 147.8$ billion for that year alone, or $31.5 \%$ of the total. Prevalence rates and their associated costs have continued to increase since the $1990 \mathrm{~s}$. The latest data available indicate that in 2005 approximately 40 million American adults ages 18 and older $(18.1 \%)$ had an anxiety disorder. These numbers do not include an additional 9\% of Americans estimated to have had a DSM-IV-TR personality disorder (Samuels, Eaton, \& Bienvenu, 2002), which includes additional anxietyrelated disorders.

Excessive social anxiety and relationship disturbances (lack of interpersonal contact and absence of close relationships) are central features of at least three different personality disorders: APD, schizoid personality disorder, and schizotypal personality disorder, although other symptoms differentiate these three disorders. In these personality disorders the individual does not enjoy close relationships with others and is socially and emotionally isolated, although underlying motivations are distinct. Excessive social anxiety and relationship disturbances are also core features of a number of anxiety-related $D S M$ categories including SP (social anxiety disorder). Such extensive overlap in symptomalogy, as well as high levels of comorbidity, may be viewed as evidence against discriminant validity and syndromic integrity, problems that are even more pronounced when considering diagnostic categories in children and adolescents, as we shall see.

Among children and adolescents the combined prevalence of anxiety-related disorders is also higher than all other mental disorders (Costello et al., 1996). The 1-year prevalence in children ages 9 to 17 is $13 \%$, including separation anxiety disorder, generalized anxiety disorder, social anxiety disorder (SP), and obsessivecompulsive disorder. However, such discrete categories of anxiety disorders may be fictional, as the comorbidity between them can be as high as 90\% (Klein \& Pine, 2002), eliminating even the possibility of an empirical demonstration of discriminant validity. For example, in a study of anxiety disorders in over 2000 Dutch children the distinctions among the types of anxiety were not found to be valid (Ferdinand et al., 2006). A number of similar affective and cognitive processes appear to be common across the entire range of these disorders including hyperarousal, hypervigilance, narrow focus of attention, overestimation of risk, and avoidance of threat (Craske, 2003). In addition to this problem of pseudocomorbidity between various types of anxiety disorders, symptoms of anxiety very commonly co-occur with depression, with comorbidity estimates as high as 50\% (Curry, March, \& Hervey, 2004; Finch, Lipovsky, \& Casat, 1989). As previously discussed by various authors (Jensen \& Hoagwood, 1997; Richters \& Cicchetti, 1993; Sroufe, 1997; Wakefield, 1997) when comorbidity becomes the rule rather than the exception, the underlying $D S M$ classification system must be questioned. This is especially true when diagnostic constructs for childhood have been downwardly adapted from models of adult psychopathology.

Of course, the problem of defining mental and personality disorders, as distinct from the vast array of normal problems that people everywhere grapple with during the course of their everyday lives, is extremely difficult. Nevertheless, these data documenting implausibly high prevalence rates and excessive comorbidity clearly necessitate a rethinking of the DSM-IV-TR as a diagnostic tool, and another major $D S M$ revision is currently underway. Some scholars believe that an evolutionary perspective may not only be helpful, but it may also ultimately be neces- 
sary to properly distinguish abnormal behavior from behaviors that fall within the normal range. For example, the harmful dysfunction analysis of Wakefield (2005, p. 891) asserts that any disorder must be (a) "Harmful, that is, negative as judged by social values; and (b) caused by a dysfunction, that is, by failure of a psychological mechanism to perform its function, in the sense of biological function."

This scheme involving two criteria implies that value judgements within any particular culture alone are insufficient to determine whether a given behavior is pathological, because a separate dysfunction criterion must also be met. Reciprocally, a biological dysfunction is also insufficient to define a disorder, unless the dysfunction is harmful to the individual. Together these two criteria could serve as a check on an undesirable proliferation of different disorders or an implausible rise in prevalence for any given disorder.

In the present context I also emphasize the necessary coordination of developmental and evolutionary perspectives, both of which are deemed essential to defining normal versus abnormal. Following the logic of developmental psychopathology, I would add a third criterion specific to defining developmental disorders: (c) harmful for the individual's future development.

Thus, extreme forms of anxious attachment are presently classifiable as a psychiatric disorder because they are harmful to the present and future well-being of the child and dysfunctional from the standpoint of not serving the biological function for which the attachment system evolved. These three criteria, although simple and straightforward, would likely give rise to various controversies and debates. Such debates may be healthy in keeping the number of different disorders and their prevalence rates from increasing to ever higher levels and for eliminating disorders that are not harmful to the individual, nor dysfunctional in the biological sense. Of course, debates over revising or reclustering $D S M$ categories do not address the more fundamental concern of viewing the individual's behavior in the context of an ongoing adaptation to a specific environment.

\section{Functionalist Approach}

As an alternative to the medical model of disease implicit in the DSM, I propose a functionalist model of social anxiety with its roots in earlier functionalist approaches to emotion in general. Toward the end of the 20th century, the field of emotion research in developmental psychology was rejuvenated by a new perspective on emotions. This change in the zeitgeist of emotion research was stimulated by earlier innovations in systems theory and human ethology, particularly attachment theory and research (Bowlby, 1969, 1973). The new functionalism (Campos, 1994), or what Sroufe (1996) called an "organizational approach," emphasized the role of emotions as regulators and determinants of both intrapersonal and interpersonal behaviors, as well as stressing the adaptive role of emotions.

Like most innovations, the "new functionalism" was not altogether new. The functionalist perspective in the new theory of emotion was reminiscent of earlier Darwinian models that emphasized the communicative and regulative functions of emotion. As noted by Campos (Campos, Mumme, Kermoian, \& Campos, 1994, p. 300), the functionalist approach was

already well established in biology, where the dependence of organisms for their existence on the presence of other organisms and the physical environment has repeatedly been demonstrated ... the new relational approach in the social sciences extends the notion of open systems to a more complex level-that of all person-environment interactions of significance to the person.

A novel idea that took hold among emotion theorists was that a basic emotion involved an invariant relationship between a type of goal and an appreciation of one's progress in relation to it. These goals may be genetically preordained (as is the goal of proximity to the attachment figure in infancy), or socially constructed (a teenager who wishes to own a car). In either case emotions were viewed as reactions to one's evaluation of the relationship between a given event and one's goals. Although goals change with development, emotion theorists posited an affective continuity that reflects the unchanging relationship between goals and emotions. An individual's emotional response may be largely determined by their memory of past experiences with the particular object, person or event, or by their expectation of what is likely 
to transpire. In this manner, emotion reciprocally influences cognition, by organizing and biasing perceptions.

This functionalist emphasis on the relation between one's goals and emotional responses was also evident at about the same time in the writing of influential emotion theorists in social psychology, such as Richard Lazarus. His cognitive-motivational-relational theory grew out of his earlier efforts to develop a cognitive approach to psychological stress and coping that focused on the phenomenological quality of stress.

According to Lazarus (1991), the person's appraisal of a situation according to his or her life goals determines the meaning of any given emotional transaction. A unique feature of his theory is the central role given to the coping process in the subjective construction of meaning, a component retained from his earlier work on stress, appraisal, and coping. Together, these developmental and social psychological theories of emotion, and their forerunners in ethology, provide a useful starting point for constructing a functionalist theory of anxiety.

\section{A Functionalist Theory of Anxiety}

To illustrate a functional theory of anxiety, examine the flow chart depicted in Figure 1. This model involves three sequential components that situate any life-relevant (anxiety-inducing) event in developmental context with respect to its past, present, and future. Antecedent factors consist of stable temperament/personality traits, the individual's developmental history, and ecological factors that may be conceptualized at various levels (Bronfenbrenner, 1979; Cicchetti \& Aber, 1998). At a microsystem level of analysis, psychologists stress the importance of close relationships and the details of the quality of interactions. At a middle (meso) level, social structures like the peer group, violent neighborhoods, social institutions like the school or workplace, and socioeconomic status variables that index available resources (or status) and fluctuating situations (such as a divorce, or job loss) are considered. Finally, at a macrosystem level of analysis, the broader culture and some of the characteristics of modern society - its fast pace, competitive, impersonal nature, and so forth-may constitute risk factors for anxiety and personality disorders.

Together, these personal and ecological factors set the stage for the cognitive/emotion process represented in the middle panel. For example, a challenging situation whose outcome is of vital importance to the individual will initiate a different emotional/cognitive process depending on one's confidence of success. The antecedent variables influence the individual's appraisal of the situation and expected outcome, which may, in turn, affect the actual outcome. Outcomes influence long-term emotional states that feed back into the flow chart and influence future events as antecedent factors. In this manner goal-relevant outcomes and recurring patterns of emotional responses largely determine a person's mental health and sense of well-being. Psychological adaptation is broadly defined in terms of these recurring patterns of responses to a developmental hierarchy of biologically relevant life goals.

This model departs from standard evolutionary models in several ways. First, anxiety is conceptualized as an active response formulated by the individual facing challenging life goals, rather than a passive response dictated by some unpredictable event. According to Nesse (2005), anxiety may have evolved as an inexpensive response system that protects against potentially costly dangers. According to his "smoke detector principle" anxiety can be annoying and inconvenient, but false alarms are far less costly than the cost of failing to respond to a genuine crisis. Thus, anxiety generally makes adaptive sense as a cost-effective response to potential threats from the environment. However, like any analogy, the smoke detector principle explains some phenomena better than others. It does a good job explaining why natural selection would tend to favor vigilance rather than nonchalance with respect to unpredictable or threatening events. Some types of anxiety related to trauma, such as posttraumatic stress disorder, seem to fit this model well. However, by casting the organism in a passive rather than active role, the analogy places too much emphasis on anxiety as "something that happens to you," rather than "something you produce" in interaction with the environment. In a functionalist 


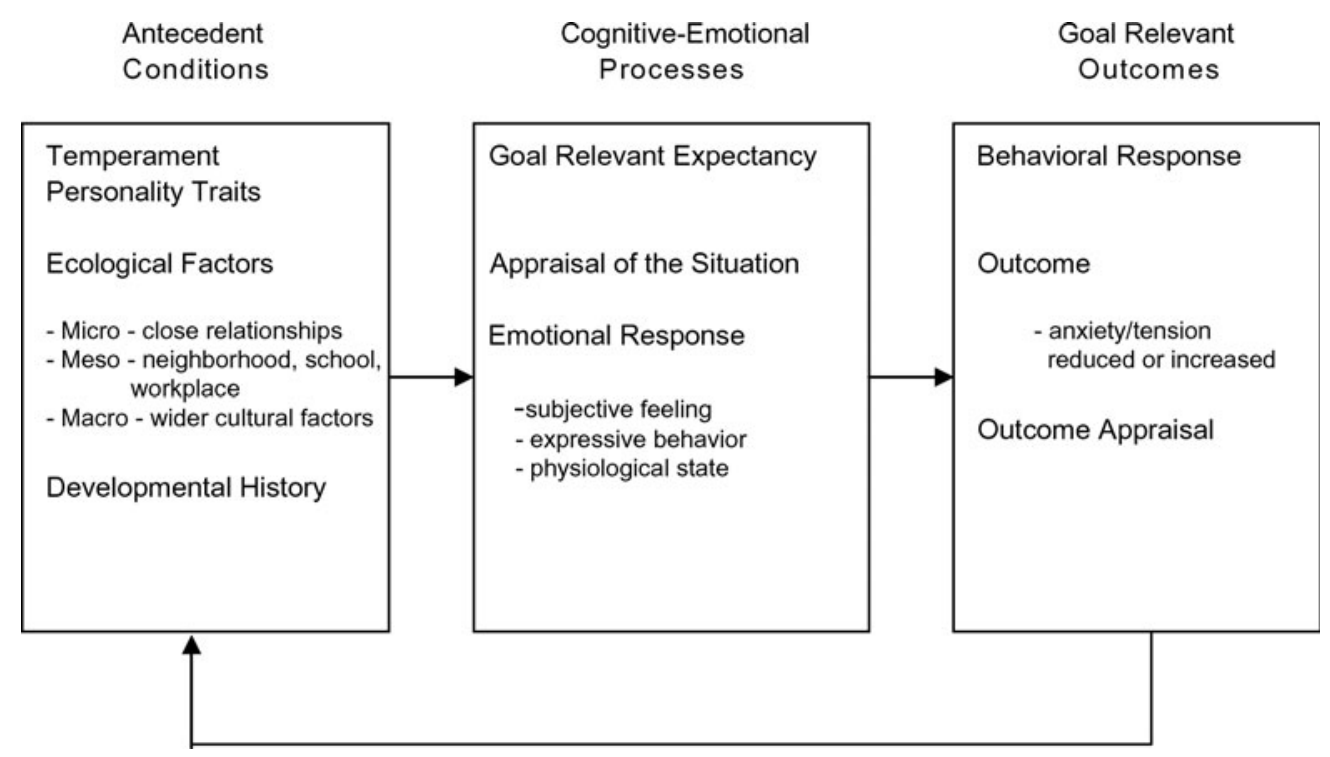

Figure 1. The functionalist model of social anxiety.

model anxiety is recast as a necessary component of an adaptive response generated by the individual as a consequence of monitoring and appraising progress or failure toward life-relevant goals of major importance.

A second departure from standard evolutionary models involves defining (and then studying) adaptation. In the proposed model the concept of "adaptation" is not defined solely in terms of survival and reproductive success (inclusive fitness). Because of the "ecological release" of contemporary society (e.g., birth control) no reasonable measure of human adaptation can be operationally defined today in such terms, although any evolutionary model must infer that our evolved species-typical characteristics were produced by differential survival and reproductive success during the formative period of our human evolution. The most basic goals of all living organisms are self-preservation and reproduction. But an evolutionary perspective goes far beyond this when it defines adaptation in reference to a developmental hierarchy of biologically relevant life goals for humans as a species. Because the adaptive problems facing any species remain largely the same across generations over deep time, they are capable of "engineering" adaptive solutions in terms of specific cognitive/behavioral/emotional systems. This is the fundamental premise of the new science of evolutionary psychology. Although universal, these adaptive problems vary by age and gender according to the life history and malefemale reproductive strategies of the human species. Thus, the earlier example of a socially constructed goal (a teenager who wishes to own a car) is recast as a biologically relevant life goal of late adolescence and early adulthood (acquiring status and resources), a goal that may be more important for adolescent boys than girls compared to, for example, relationship goals. Indeed, much evidence would suggest that many life goals, with the exception of attachment in infancy, show some degree of sexual dimorphism in the human species, as they do with nonhuman primates, and mammals in general.

To illustrate the relation between life goals and anxiety let us examine what many consider to be the prototypical case of anxiety in infancy. One of the first evolutionary psychologists, John Bowlby (1969), proposed that infants would more readily respond with fear to events or situations that provided the infant with "natural clues to danger" such as being left alone. Consequently, the infant's response to separation has received considerable scrutiny by researchers. Data from primate (including human) studies indicate that separation from the 
mother is associated with changes in the infant's level of activity, heart rate, play, and affective expression. Ethologists view these infant responses as functionally significant in terms of their signal value as well as the regulation of internal state. Facial, vocal, and other nonverbal displays often elicit caregiving from others. The protest and crying of infants to separation typically results in their caregiver's return, followed by soothing and attention, and the communicative function of these displays is self-evident.

Depressed activity might also serve an adaptive function if protest has been unsuccessful in bringing about the caregiver's return. A primate infant in the wild who is separated from its mother and alone is extremely vulnerable. The reduced activity level allows the infant to recover from agitation that is costly in terms of energy depletion. Another cost of continued crying may result from drawing unwanted attention from potential threats in the environment that would be increased as a result of continued activity and exploration. It appears that natural selection has equipped the infant with a conditional strategy that first calls for a vigorous attempt to reestablish the care and protection of the parent or another member of the social unit. Should this fail, a second strategy is enacted that leads to depressed levels of activity to reduce energy depletion and the probability of harm until help is forthcoming (Izard, 1991; LaFreniere, 2005).

Separation anxiety emerges according to a developmental timetable that makes adaptive sense from a life history perspective. By the end of their first year infants have become increasingly active in their relationship with the caregiver as well as increasingly mobile. With this new mobility the infant expands the capacity for eager exploration of the outer world, returning to the caregiver as a "secure base" (Ainsworth, 1967). At just this age separation anxiety begins to peak in infants from diverse cultures. Separation anxiety near the end of first year of life is an example of a biologically driven, species-typical adaptive response to the infant's loss of protection. Because all infants experience this anxiety to some extent, part of their emotional makeup, including their emerging ability to regulate anxiety, is shaped by their experiences with the primary caregiver surrounding such separations and reunions.

\section{Developmental Pathways to APD}

If separation anxiety serves as a prototype, many other types of anxiety exist across the life span and a number of different pathways to both anxiety and personality disorders are plausible. It is thus not surprising that during the first half of the 20th century, anxiety (neurosis) was considered to be the hallmark of a personality disorder. Subsequently, anxiety or mood disorders were classified on a separate axis in the $D S M$ from personality disorders. It may be time to reconsider the implications of this modification, at least with respect to APD.

Although anxious-resistant attachment in infancy is characterized by angry rejection and opposition to the caregiver, in adolescence it is related to anxiety disorder classifications (not oppositional defiant disorder) as predicted from the infant's necessary pattern of hypervigilance of an inconsistent caregiver (Warren, Huston, Egeland, \& Sroufe, 1997). Longitudinal research has established that the pattern of anxious-resistant attachment in infancy is a risk factor for childhood internalizing behavior problems in general, including anxiety, high dependency on adults, social withdrawal, passivity, and submissiveness with peers (Erikson, Egeland, \& Sroufe, 1985; LaFreniere \& Sroufe, 1985; Lewis, Feiring, McGuffog, \& Jaskir, 1984; Shamir-Essakow, Ungerer, \& Rapee, 2005; Sroufe, Egeland, Carlson, \& Collins, 2005; Sroufe, Fox, \& Pancake, 1983).

During childhood, a parent's chronic negative emotions toward the child are thought to reflect existing dysfunction and contribute to future deviation. Deviations from an optimal goal-directed partnership involving mutuality and give and take between parent and child, as well as firm limit setting when necessary by the parent, may be viewed in terms of the balance of power in the parent-child relationship. At the microecological level of analysis, research has shown that mothers of anxiouswithdrawn preschoolers can be overcontrolling and intrusive, particularly in situations that call for mutuality and negotiation, rather than the exercise of parental authority (LaFreniere \& 
Dumas, 1992). In an observational study using conditional probability analyses, mothers of competent and anxious-withdrawn children all responded reciprocally to their child's aversive behavior and negative affect. However, the context of this negative reciprocity was quite different for different children. Negative maternal affect had a very different meaning for the anxious-withdrawn child because of stark differences in the emotional qualities characterizing this relational context. Because of the chronically low base rate of positive affect of the mothers of anxious-withdrawn children, no signal could be sent to their child by lowering it still further. Only an increase in negative affect, from an already high base rate could be used, and this maternal negative affect had little signal value for the child because it could not be distinguished from the general background pattern of negativity. Finally, even a positive response by the child to the mother's signal was likely to result in a negative maternal response. From a behaviorist standpoint, the child's attempts to establish positive rapport are likely to be extinguished in the absence of reinforcement from the mother, and anxious responses are conditioned by repeated criticism, disapproval, and negative affect. Because even compliant behavior is likely to result in a negative maternal response, the child is caught in a nowin situation, producing frustration, conflict, and ultimately a sense of resignation and avoidance on both sides of the relationship. Because this type of parent-child interaction was typical of anxious-withdrawn children, it is likely that it constitutes an important environmental risk factor for later social anxiety or APDs, particularly if the child generalizes avoidance of the parent to peers and other social partners. Viewed from a functionalist perspective the child's cycle of repeated effort and failure to win the approval and affection of the parent will exert an impact on both the child's relationship to the parent and the development of their sense of self-worth and social confidence. It is on this basis that a connection to more general and enduring patterns of future avoidance may be predicted.

By late adolescence and adulthood the diagnosis of APD is possible. This disorder is characterized by a long-standing pattern of feelings of inadequacy, extreme sensitivity to what other people think about them, and social inhibition, and includes a majority of the following symptoms: avoids occupational activities that involve significant interpersonal contact, because of fears of criticism, disapproval, or rejection; is unwilling to get involved with people unless certain of being liked; shows restraint within intimate relationships because of the fear of being shamed or ridiculed; is preoccupied with being criticized or rejected in social situations; is inhibited in new interpersonal situations because of feelings of inadequacy; views self as socially inept, personally unappealing, or inferior to other; is unusually reluctant to take personal risks or to engage in any new activities because they may prove embarrassing (American Psychiatric Association, 2000).

Alternatively, the same developmental history allows a straightforward prediction to the onset of social anxiety disorder (formerly SP). Social anxiety disorder is characterized by overwhelmingly anxiousness and excessive selfconsciousness in everyday social situations. Individuals with social anxiety disorder have an intense, persistent, and chronic fear of being watched and judged by others and of doing things that will embarrass them. They can worry for days or weeks before a dreaded situation. This fear may become so severe that it interferes with work, school, and other ordinary activities, and can make it hard to make and keep friends. It exceeds normal "shyness" as it leads to excessive social avoidance and substantial social or occupational impairment. Feared activities may include almost any type of social interaction, especially small groups, dating, parties, talking to strangers, restaurants, and so forth (NIMH, 2009). Despite being organized on an entirely different axis, the descriptions of these two DSM diagnostic categories are remarkably similar. Longitudinal research on the etiology of these two disorders could play an important role either in eliminating redundant of overlapping DSM categories, or in the establishment of etiologically distinct disorders with sufficient discriminant validity. Certainly the existence on nonexclusive categories in the DSM undermines the conduct of research in developmental psychopathology that aims to identify specific pathways to specific disorders. 
Let us examine this research problem in more detail.

The specific form that an adult disorder will take is not predictable from early socialization patterns alone, but by the entire developmental history of the individual (up to the point of onset of the disorder), and by the influence of genetic factors in interaction with ongoing changes in the environment. Only the most painstaking longitudinal prospective research can help clarify the main outlines of any hypothesized developmental pathway leading from childhood behavioral and emotional problems to adult personality disorders. Repeated measures of the experiential aspects of the child's social environment prior to the onset of disorder must be captured with developmentally appropriate constructs and methods. Rarely is such costly research undertaken. Even when such research is carried out, the excessive degree of comorbidity that reflects underlying problems of discriminant validity in both childhood and adult disorders undermines the identification of specific pathways leading to specific disorders, including both biologic and developmental trajectories.

As a result, our current understanding of the developmental risk factors associated with the eventual onset of adult personality disorders is rudimentary, with the exception of antisocial personality disorder for which an extensive developmental database exists. There is evidence that in adolescent development less serious forms of antisocial behavior or substance abuse precede the onset of more serious acts. This reflects the basic hierarchical and developmental feature of psychopathology: less serious manifestations precede the more serious manifestations of deviance (Cicchetti, 1990). Not all individuals progress to the most serious outcome(s); typically, increasingly smaller numbers of individuals reach more serious levels within a pathway. Individuals who reach a more serious level in a pathway will often still display behaviors characteristic of earlier levels (Loeber, 1991).

With respect to internalizing disorders a preliminary strategy would be to identify the most common developmental pathway, within the branching tree analogy, the main trunk. It seems likely that the main trunk of an eventual tree of related anxiety and personality disorders may be a problem of adaptation that I will refer to as the anxiety-avoidance-isolation sequence. This concept represents a typical sequence of behavioral adaptations that begins with a normative response of anxiety to an important social goal involving relationships. This may occur in infancy in relation to the caregiver, in childhood in relation to peers, in adolescence with respect to heterosexual relations, or in adulthood in the workplace. Repeated failures to achieve the goal give rise to avoidance of those social situations that trigger the conditioned anxiety, a response that places the individual at risk for increasing social isolation. Finally, isolation itself exacerbates future risk for more serious problems that stem from stressful events and the lack of protective factors like a close personal confidant. As a trunk of a much more differentiated tree, the anxiety-avoidanceisolation sequence may eventually include branches that lead to social anxiety disorder, APD, generalized anxiety disorder, some combination of these, or other specific personality disorders. Comorbidity takes on a somewhat different meaning within this dynamic approach to classification because it becomes an expected result as more serious complications arise during the life course.

With respect to the well-known comorbidity between the DSM-IV-TR concepts of APD and SP, Reich $(2000,2009)$ has summarized empirical findings that unequivocally support the merger of these two DSM-IV categories. Of 13 studies reporting their comorbidity, the average was $56 \%$ (range $=22-89 \%$ ). These findings were based on a wide range of populations using different measurement instruments in many settings. Reich concludes that "Given that this is about the same level of agreement that might be found when comparing two different $D S M$ personality measurement instruments on the same population and that subthreshold cases usually were not taken into account, this probably represents the highest level of overlap we could expect from these diverse settings and measurement techniques. It seemed clear that SP overlapped highly, if not completely, with APD (Reich, 2009, p. 91).

There are number of other empirical studies on the relationship of APD to SP. An Australian epidemiological study of more than 10,000 
participants compared SP with APD and found a high degree of symptom overlap (Lampe, Slade, Issakidis, \& Andrews, 2003). Those with more significant APD and SP symptoms had deficits in their ability to form relationships and gain employment and had more comorbid anxiety and depressive disorders. A longitudinal study of personality disorders found a significant association between APD and SP, and concluded that because these two groups did not differ appreciably in symptoms, that APD and SP may be alternate conceptualizations of the same disorder (Ralevski, Sanislow, \& Grilo, 2005). Similarly, a Swedish self-report epidemiological study examined the overlap of APD and SP and found that the disorders were similar, with the major difference being a decrease in function in the APD (Tillfors, Furmark, Ekselius, \& Fredrikson, 2004). Finally, Hummelen, Wilberg, Pedersen, and Karterud (2007) found that SP was more strongly associated with APD than with other personality disorders, whereas APD showed stronger associations with SP than with other symptom disorders. Together these studies indicate that APD and SP do not have significant differentiating features and may be the same disorder, only with somewhat more severe symptoms in APD.

A recent twin-study of the genetics of APD and SP examined 1427 female twin pairs and reported that the genetic basis of the two disorders was identical in their female sample (Reichborn-Kjennerud et al., 2007). Besides having virtually the same symptoms and genetic basis, the two disorders also respond to the same pharmacologic and psychotherapeutic interventions (Reich, 2009). Reich and others conclude from this empirical evidence that no dividing line exists between APD and SP, with APD merely being the more severe form of the same disorder. A straightforward developmental hypothesis would therefore begin with an anxiety-avoidance-isolation sequence that becomes chronic, and over time progresses to SP and possibly to APD. However, other results suggest a more complex and differentiated developmental pathway than a simple progression of severity along the same dimension. APD has been found to be associated with a broader array of symptoms and interpersonal problems than SP, including eating disorders, whereas SP has been more strongly associated with panic disorder than was ADP (Hummelen et al., 2007). One could conclude that the APD diagnosis involves a wider array of symptoms and personality features pointing toward more severe personality dysfunction. However, this same evidence could also be interpreted to indicate that as the common trunk of social anxiety grows more severe over the life course it also becomes more highly differentiated. Additional factors like gender, ongoing life stressors, developmental history, and other environmental risk factors could influence the specific pathway the disorder takes as development proceeds, with a wider range of outcomes possible, including the entire range of anxiety disorders, eating disorders, depression, agoraphobia, APD, as well as other personality disorders.

\section{Genetic Contributions}

Based on crossfostering studies in primates demonstrating that heritable contributions to anxiety and negative affect are always incubated in the context of early experience (Suomi, 2000, 2005), it is likely that the development of childhood anxiety disorders and later personality disorders involve Gene $\times$ Environment interactions (Rutter, 2006). Nevertheless, it is clear that genetic contributions to the development of anxiety and negative affect constitute a heritable vulnerability to anxiety and personality disorders and justify widespread interest in both molecular and behavior genetics.

The dopamine D4 receptor (DRD4) is a critical gene in psychiatric genetics because of its neuroanatomical connections and its involvement in the physiology of behavior, pharmacological response, and psychopathology. The DRD4 gene codes for a protein that is distributed in the frontal cortex, striatum, hypothalamus, and hippocampus. The DRD4 polymorphism has been studied in association with illnesses like schizophrenia, attention-deficit/ hyperactivity disorder, obsessive-compulsive disorder, bipolar disorder, and recently, APD. For example, Joyce et al. (2003) investigated whether polymorphisms of the DRD4 and dopamine D3 receptors (DRD3) were associated with personality disorder symptomatology. Based on DNA samples obtained from 145 
depressed patients, the 2-repeat allele of the DRD4 exon III polymorphism and the T,T genotype of the $D R D 4-521 \mathrm{C}>\mathrm{T}$ were each associated with increased avoidant and obsessive personality disorder symptoms. Questions remain, however, concerning the degree of association and the practical importance of genomics with respect to treatment.

Four "perspective" articles recently published in the New England Journal of Medicine discussed the pros and cons of genomic studies. The problem addressed in the commentaries is that the physical and psychiatric disorders under investigation were expected to be directly associated with genetic variations that are common in the population. The principal rationale to decode the human genome was that it would lead to the discovery of the variant genes that predispose people to various diseases. This idea, called the common disease/common variant hypothesis, drove major developments in biology over the last 5 years. Thus far, more than $\$ 3$ billion has been invested in approximately 100 genomewide association studies, often involving thousands of patients in several countries. Although some common genetic variants have been found, in almost all cases they carry only a modest risk for the disease. Now, after 5 years of investigation, the search for common variant has been widely judged a failure.

Goldstein (2009) concludes that if there were any common gene variants responsible in a major way for chronic diseases, they would have been found already. He assumes that all single nucleotide polymorphisms (one-base variations in the genome) yet to be discovered will have even weaker effect sizes than the weakest so far found. In his view the search for a genetic basis of common diseases must be shifted to identifying rare genetic variants. In his view, schizophrenia, for example, would be caused by combinations of 1,000 rare genetic variants, not of 10 common genetic variants. Such circumstances would undermine the position of those who argue that the common variants detected so far, even if they explain only a small percentage of the risk, will nonetheless identify the biological pathways through which a disorder emerges, and hence point to corrective drugs.
Even the defenders of such studies do not dispute that, thus far, they have failed to realize the widely broadcast promise that genomics would revolutionize clinical medicine. Kraft and Hunter (2009) argue that genome-wide association studies remain valuable, but they acknowledge that those polymorphisms discovered to date do not have much diagnostic utility, because the great majority of the newly identified risk-marker alleles confer very small relative risks and are found in only small portions of the population. In principle, the genetic effects on personality traits and disorders are likely to be important, but findings to date are inconsistent and at best account for a tiny percentage of the individual variation, a situation that suggests that these genetic effects may be dependent upon environmental risk factors and triggers.

Regardless of the fate of the search for common genetic variants underlying specific psychiatric disorders, research in behavioral genetics is likely to remain vital because twin studies provide an important window on the direct influence of genes on whole organisms and will continue to compliment studies in molecular genetics. Broadly speaking, behavioral genetics research on temperament, personality, and personality disorder yields moderate heritability estimates, but like the genome-wide association studies, the hope that such research would help to clarify developmental pathways to personality disorders has not yet been justified (Rutter, 2006).

We do know that genetic contributions to personality traits like shyness and behavioral inhibition are typically moderate, accounting for 40 $50 \%$ of the variance, subject to the usual caveats regarding estimates derived from behavior genetic studies. Daniels and Plomin (1988) proposed that heredity influences individual differences in shyness more than in any other personality trait. Results from the MacArthur Longitudinal Twin Study (Emde et al., 1992), which assessed 200 identical and fraternal twin pairs at 14 months, show a great deal of variability in the estimates of genetic heritability of infant temperament. Consistent with previous findings, this research indicates that the tendency to express negative emotions is highly heritable, but mostly when parental reports 
provide the data, and when uncorrected estimates are used. For example, the high heritability estimate for parent ratings of shyness (.82) that they report derives primarily from the lack of any concordance between dizygotic twins $(-.03)$, rather than exceptionally high concordances between monozygotic twin pairs (.38). Because a negative correlation between dizygotic twins violates the model's assumptions, their second, more conservative estimate of .28 is probably more accurate than the uncorrected estimate (.82). It is simply illogical to base an argument for strong heritability of any trait on the absence of similarities found between fraternal twins. Observational data on shyness and behavioral inhibition provide more stable estimates ranging from .49 to .62 . As the data from the MacArthur study attest, it may not be possible to produce a single definitive heritability estimate for shyness and behavioral inhibition. Still, there should be no doubt that genes contribute substantially to this stable personality trait.

As a consequence of the relatively high heritability of personality traits demonstrated by behavioral genetics research, psychobiological models of inherited temperament and personality traits must consider the evolutionary basis and adaptive significance of these individual differences, or the question: why did personality types evolve in the human species in the first place? Because natural selection tends to produce genetically homogeneous populations with regard to adaptively important traits, this relatively high genetic variance associated with human personality remains an enigma. Evolutionary psychologists like MacDonald (1995) conceptualize personality as a set of evolved systems designed to solve problems of adaptation during our evolutionary past because even the most primitive animals need behavioral systems designed to obtain resources (Panksepp, 1998). The most common behavioral approach systems are designed for obtaining food and mates, but more advanced species might also be designed with systems for obtaining other resources, social status, or dominance within the group. Other systems are designed to deal with threats, the most important of which are fear systems that have been studied in a wide range of animals. Finally, there must also be a system of arousal regulation designed to energize the organism to meet environmental challenges or opportunities, but also designed to turn off when conditions return to normal. Virtually all mammals have these three systems: behavioral approach, behavioral inhibition, and arousal regulation (Gosling \& John, 1999; MacDonald, 1995). In humans, variation in these ancient personality dimensions approximate bell-shaped normal curves, and as we move out toward the extremes of personality dimensions, we are more likely to see pathological conditions. However, these three dimensions also show distinct patterns of variation between the sexes throughout the mammalian class as a result of sexual selection.

\section{Sex Differences in Personality}

The Darwinian concept of sexual selection, particularly intermale competition, and the more recent theory of parental investment (Trivers, 1972) lead to the prediction that males will generally pursue relatively high-risk strategies compared to females, and will thus be higher in behaviors typical of behavioral approach systems (dominance/sensation seeking, risk taking, impulsivity, exhibitionism) and lower on behavioral inhibition systems (fear, wariness, caution, safety seeking; MacDonald, 1995). The particular dynamics of sexual selection for any given species are shaped by the reproductive efforts of the two sexes constrained by the physical and social ecology. Reproductive effort involves three different costs: mating (including attracting and competing for mates); parenting (including feeding, care, and protecting offspring) and in some species, such as humans; and nepotism (helping relatives to survive and reproduce more successfully). Because mammals are characterized by internal gestation and a high degree of postnatal maternal care, parental investment of females throughout the mammalian class greatly exceeds that of males. Life history theory is concerned with how each species evolves a resource allocation plan to deal with the inevitable trade-offs involved in balancing survival, growth, and reproduction at each age in the life cycle. In all mammals, including humans, this plan is sexually dimorphic with respect to sexual organs, 
body size and proportion, brain anatomy, the endocrine system and physiology, age at sexual maturity, and a number of personality and psychological traits. Based on this model, ethologists and evolutionary psychologists are interested in studying patterns of early gender differentiation in behavioral approach, behavioral inhibition, resource competition, social interaction in peer groups, and so forth.

Developmental research in children has produced a wealth of evidence that is generally consistent with predictions derived from parental investment theory (for extensive reviews, see Geary, 1998; LaFreniere, 2000). Research relevant to the behavioral approach system has consistently demonstrated that compared with girls, boys are more physically active from an early age, more assertive; more physically aggressive, competitive and dominant with peers, and more oppositional with adults. Boys are also more likely to take physical risks, engage in more rough-and-tumble play, and more highenergy sociodramatic play involving guns and superheroes. In contrast, research on the behavioral inhibition system has shown that preschool girls are more compliant to parents and teachers, and rated by them as more socially competent. Girls rate themselves as more fearful, timid, nurturant, and empathic than do boys. Parental ratings indicate that when sex differences are found in fearfulness and timidity, parents rate girls as more fearful than boys, and as more cautious in situations involving risks as noted above.

In addition to these well-documented sex differences in behavioral approach and behavioral inhibition systems, Barlow and colleagues postulate that girls, compared to boys, may have a greater psychological vulnerability to experience a diminished sense of control and accompanying anxiety that arises out of early life experiences (Barlow, 2002; Chorpita \& Barlow, 1998). Gender differences in the prevalence of anxiety and mood disorders might then be traced to a heightened psychological disposition to experience salient events as unpredictable and uncontrollable. These early experiences may mediate the emergence of anxiety and depression early in development by fostering a cognitive bias that operates as an amplifier for stressful life events. There is some evidence that these experiences differentially affect girls compared to boys, potentially accounting for the fact that the prevalence of anxiety or mood disorders in women exceed that of men by $2: 1$ (Barlow, 2002; Craske, 2003; Crick \& Zahn-Waxler, 2003; Kessler et al., 2003; Nolen-Hoeksema \& Girgus, 1994). Some girls may learn early on that their behavior has less impact on their environment than the behavior of boys. It is these factors that are thought to contribute to a sense of uncontrollability in girls and foster the development of pessimistic attributional styles, a cognitive style that could place girls at higher risk for later internalizing disorders. The constellation of affective-cognitivebehavioral risk factors, including chronic anxiety, ruminative coping, pessimism, and a pattern of generalized learned helplessness in adolescent girls, may constitute a sexually dimorphic developmental pathway that leads from normative anxiety to clinical anxiety and/or depression (Crick \& Zahn-Waxler, 2003; NolenHoeksema, 1998).

\section{Sex Differences in Brain Function}

Sex differences that are found across a wide range of cultures are often mediated by evolved mechanisms in the brain and endocrine system that were designed by natural and sexual selection to enhance the behavioral adaptation of the organism in the environment of evolutionary adaptedness (EEA). Predictably, sex differences have been discovered in brain structure, neurochemistry, and function in every lobe, including regions centrally implicated in emotional and cognitive processes such as the hippocampus, amygdala, and neocortex (for a recent review, see Cahill, 2006). These sex differences are not only produced by circulating hormones but also by the organizing effects of sex hormones released during prenatal development and direct genetic effects that are not mediated by hormones. Because selection pressures can operate on females and males in both similar and quite different ways, we should expect a priori that brain organization and function should be both highly similar in some basic processes and markedly different in others. This is precisely the pattern of empirical results that is now accumulating at an increasingly rapid rate because of technical and methodological advances. 
Recent imaging studies reveal anatomical sex differences in various regions throughout the human brain. In women, parts of the frontal cortex and limbic cortex are denser and the hippocampus is larger, whereas in men, parts of the parietal cortex and amygdala are larger than in women. In addition to size differences in discrete structures of the brain, researchers are also documenting anatomical sex differences at the cellular level. Such anatomical diversity may be caused in large part by the organizing activity of sex hormones during prenatal development. Positive correlations between brain region size in adults and sex steroid action in utero suggest that at least some sex differences are already present at birth.

In several important ways, sex differences in the brain's chemistry and construction influence how males and females respond to the environment, including reacting to stressful events and remembering such events. Once again, sexual dimorphism is evident in structure, function, and neurochemistry. Positron emission tomography (PET) scans reveal that the brains of males produce serotonin, which enhances mood, at a faster rate than those of females. A PET scan study at the National Institutes of Mental Health showed that serotonin production was a remarkable $52 \%$ higher on average in men than in women (Nishizawa et al., 1997). Results such as these might help clarify why women are twice as likely as men to experience mood disorders that involve serotonin dysfunction, and which are commonly treated with drugs that boost the concentration of serotonin. Adequate brain levels of serotonin are directly associated with emotional stability, an inner sense of well-being, relaxation, and restful sleep, whereas low levels of serotonin are associated with many symptoms of anxiety and depression. An unanswered evolutionary question is why gender-specific selection pressures produced this particular neurochemical sex difference, that is, what adaptive function might it have served?

Besides anatomical differences in the hippocampus and amygdala, functional differences can sometimes involve opposing effects for males and females. For example, a brief exposure to stressful learning conditions produces an increase in neural interconnections in the hippocampal region in males, but a decrease in females (Shors, 2002), a result that has now been replicated in humans using Pavlovian conditioning (Jackson, Payne, Nadel, \& Jacobs, 2005). Another example of opposing effects by gender involves the amygdala. In a recent experiment with rodents, male and female pups were temporarily separated from their mothers. Maternal vocalizations produced an increase in the serotonin receptors of the amygdala in male pups, but a decrease in female pups (Ziabreva, Poeggel, Schnabel, \& Braun, 2003).

Other studies now document sex differences in amygdala function beyond the well-established finding that the amygdala is larger in men than in women (correcting for total brain size). In rats, the neurons in this region make more numerous interconnections in males than in females (Foote \& Seibert, 1999). Such anatomical dimorphism would be expected to produce differences in the way that males and females react to stress. Extensive research in rodents and humans has also shown that the amygdala functions to modulate memory storage of emotionally arousing events through interaction with endogenous stress hormones (Cahill, 2006; McGaugh, 2004). This provides the organism with an evolutionary adaptation by creating memory strength proportional to the importance of the event to the organism.

\section{Sex Differences in Hormones and Behavior}

Throughout childhood the levels of circulating sex hormones do not differ much between the sexes, and as a result, biosocial theories predict fewer biologically based human sex differences during this period than after puberty. An exception to this general principle is found in experimental research on rats and rhesus macaques demonstrating a direct influence of prenatal sex hormones on animal play. Prenatal exposure to higher levels of androgen in females is related to increased rough-and-tumble play, regardless of rearing environment (Geary, 1998). In humans, researchers have similarly demonstrated a direct influence of sex hormones on gender differences in two types of play in early childhood: allo-parenting and rough-and-tumble play (Collaer \& Hines, 1995). Play is so ubiquitous in mammals that questions regarding the function 
of this high-energy activity must be addressed. Ethologists generally regard play as providing delayed benefits to the individual because adult skills critical to survival and reproduction are practiced. In humans, a general pattern of results in both preindustrial and industrial societies reveals consistent sex differences in rough-andtumble play favoring boys and allo-parenting favoring girls. Cross-cultural research indicates that although the magnitude of these sex differences varies across cultures, the direction of the differences is constant (LaFreniere et al., 2002).

Puberty is the time of greatest sex differentiation in morphology and behavior, as it functions to prepare adolescent boys and girls for their respective reproductive roles. Evolutionary theories predict that at puberty one would begin to see increasingly marked patterns of disorder along gender lines. This is not to say that prevalence patterns of some childhood disorders like autism, conduct disorder, or attention-deficit/hyperactivity disorder (3-10 times higher in boys than girls) would not be gender-differentiated before puberty. However, systematic research on social anxiety in early childhood reveals little or no gender differentiation with respect to anxious and withdrawn behavior. This pattern changes dramatically after puberty, with adolescent girls showing greater prevalence rates of anxiety-related disorders and internalizing disorders in general (2-10 times higher in girls than boys) that persist across adulthood. There is little doubt that socialization and cultural factors exert an influence on these outcomes for boys and girls. However, many social behaviors, such as sex, aggression, fear, parental behavior, and social bonding, are also mediated by neuroendocrine systems. Androgens increase aggressiveness and self-confidence, and they rise in response to competitive situations in male mammals. In a threatening situation, male testosterone levels rise, apparently to bolster the man's self-confidence and aggressiveness as he faces a challenger. Cortisol and sympathetic division activity also increase, to mobilize the male for exertion (Weisfeld \& LaFreniere, 2009).

In such a situation, however, women often experience another hormonal reaction: a rise in oxytocin. This bonding hormone induces a "tend and befriend" response, which is to pro- tect one's children or to seek protection from others (Taylor, 2006). In mammals, oxytocin has been shown to increase affiliation, maternal behavior, grooming, and bonding to conspecifics present when the oxytocin was administered. Oxytocin seems to reduce stress: to lower cortisol and sympathetic division activity in animals and people, such as breastfeeding women, women who receive frequent hugs from partners, and men given exogenous oxytocin. Thus, oxytocin seems to reduce the physiological mobilization of stress, to provide an alternative behavioral strategy to fighting or fleeing. The effects of oxytocin seem to be greater in women than in men. Consistent with this sex difference, estrogen potentiates the action of oxytocin. From an evolutionary perspective it is vital that developmental psychologists (and psychopathologists) consider the adaptive function of these evolved systems as they may provide the missing link to their quest for understanding sex differences in normative and dysfunctional behavior.

In conclusion, three sets of factors - sex differences in the brain, hormones, play, social behavior and personality systems; different life goals related to differential reproductive strategies; and differential socialization experiences-lead to the prediction that many anxiety related disorders will be gender-differentiated after puberty. Other disorders that have similar prevalence rates for men and women, such as APD, may have gender-distinct dynamics, and may require different types of treatment.

\section{Evolutionary Psychiatry and the Mismatch Hypothesis}

One final factor from an evolutionary perspective on social anxiety pertains to modern societies in general. Because the formative period of human evolution predates the modern era, it introduces an underlying cause for the widespread prevalence of modern personality and mood disorders involving anxiety and depression that is widely referred to in evolutionary psychiatry as the "mismatch hypothesis" (McGuire \& Troisi, 1998; Nesse, 2005; Troisi, 2008). Mechanisms designed by natural selection to serve specific functions are not perfect, and may under certain circumstances go awry. 
These circumstances may be more frequent in novel environments that are far different than the human EEA. For this reason evolved mechanisms may not necessarily generate adaptive behavior today. The human EEA is sometimes specified as the African savannah during the Pleistocene. However, strictly speaking, the EEA is not a specific place or time, but rather the composite of all selection pressures that produced an adaptation. Thus, the EEA for one human adaptation may be different from that for another. The limbic system that governs our basic emotions evolved during the mammalian radiation 200 million years ago, but the biology underlying human male provisioning of offspring is not shared with other mammals and arose during the human EEA within the past 2 million years. Many human adaptations, particularly those mediated by the neocortex and exclusive to us (e.g., language), must have evolved relatively recently, because the constellation of design features that make human speech possible exists in no other species.

To the extent that the present-day environment of humans has changed from that of our EEA, some mechanisms may actually be a source of maladaptation. An example of such a mismatch would be our tendency to enjoy sweets. Such a taste may have once been adaptive in an environment where fruit was scarce, but it can now generate maladaptive behavior in an environment with a ready supply of sugar and artificial sweeteners. Despite such problems, such a tendency is likely to persist indefinitely in the future of our species, because there is no mechanism available for the rapid deevolution of once adaptive traits. Following this evolutionary logic, the prevalence of anxiety in contemporary life may be increasing because of our modern, fast-paced, competitive, and impersonal society mismatched with our evolved tendencies for communal life in our ancestral environment. In this "novel" environment, unpredictable or threatening situations may give rise to anxiety, which takes the form of a heightened sensitivity to indicators of potential danger. Unlike fear, there is no clear and present danger, and no clear and immediate response, such as flight. Because the danger or threat is not clearly perceived, no precise course of ac- tion is warranted, but a generalized uneasiness persists. Natural selection may not have adequately prepared us for the stress of life in crowded cities of 10 million people where anxiety responses are frequent, but in which potential threats are never evaluated carefully enough to reduce their frequency.

As noted in the introduction, prevalence rates for social anxiety are on the rise, particularly for young people, and in affluent Western societies. One of the most significant aspects of an evolutionary perspective is to raise questions about features of contemporary society that create conditions for such widespread maladaptation. At the macroecological level of analysis, several features of modern society may contribute to an increased prevalence of anxiety and personality disorders, particularly the relative absence of community.

Social support is a well-known protective factor for anxiety and depression in that it reduces the probability of its onset whatever other risk factors may be operating. It follows that if more people today live in social isolation without effective social support that they are vulnerable to severe anxiety and depression when the inevitable problems of life arise, whatever these precipitating stressful events may be. In this view, it is not the existence of stressful events per se that explain the increase in prevalence rates of anxiety and depression, but the disintegration of supportive communities and the increased degree of social isolation. According to Wright (1994), 25\% of households in the United States in the 1990s consist of a single person, compared to $8 \%$ in 1940. It would be difficult to argue that the stresses of the widespread poverty of the Great Depression and the uncertainties and sacrifices of WWII were relatively insignificant stressors compared to the stress of contemporary American life. It would not be difficult to argue that the urban neighborhoods of that era provided more supportive networks of family and friends than those of today.

Evolutionary psychologists extend this same line of reasoning back in time to our ancestral past. Anthropological accounts of existing hunter-gatherer societies like the IKung San of Southern Africa or remote agrarian small-scale societies reveal a high degree of social cohesion and relative absence of depressive symptoms. 
In these relatively small groups that typify life in our ancestral past, people live in close contact with an extended family of kin and neighbors for most of their lives. They may move to a neighboring village and join a new family network upon marriage or return to their own if separated. From birth until death they remain immersed in a stable and supportive community. Rivalries and tensions may exist, but they are generally open and frequently resolved in short order (Wright, 1994). Viewed from this

\section{References}

Ainsworth, M. D. (1967). Infancy in Uganda: Infant care and the growth of love. Baltimore, MD: Johns Hopkins University Press.

American Psychiatric Association. (2000). Diagnostic and statistical manual of mental disorders (4th ed., text revision). Arlington, VA: Author.

Barlow, D. H. (2002). Anxiety and its disorders: The nature and treatment of anxiety and panic. New York: Guilford Press.

Bowlby, J. (1969). Attachment and loss: Vol. I. Attachment. New York: Basic Books

Bowlby, J. (1973). Attachment and loss: Vol. II. Separation, anxiety, and anger. New York: Basic Books.

Bronfenbrenner, U. (1979). The ecology of human development: Experiments by nature and design. Cambridge MA: Harvard University Press.

Cahill, L. (2006). Why sex matters for neuroscience. Nature Reviews: Neuroscience, AOP. Advance online publication. doi:10.1038/nrn1909.

Campos, J. (1994, Spring). The new functionalism in emotion. SRCD Newsletter.

Campos, J., Mumme, D., Kermoian, R., \& Campos, R. (1994). A functionalist perspective on the nature of emotion. Monographs of the Society for Research in Child Development, 59(2/3, No. 240).

Chorpita, B. F., \& Barlow, D. H. (1998). The development of anxiety: The role of control in the early environment. Psychological Bulletin, 124, 3-21.

Cicchetti, D. (1990). An historical perspective on the discipline of developmental psychopathology. In J. Rolf, A. Masten, D. Cicchetti, K. Neuchterlein, \& S. Weintraub (Eds.), Risk and protective factors in the development of psychopathology. New York: Cambridge University Press.

Cicchetti, D., \& Aber, J. L. (1998). Contextualism and developmental psychopathology. Development and Psychopathology, 10, 137-141.

Collaer, M. L., \& Hines, M. (1995). Human behavioral sex differences: A role for gonadal hormones during early development? Psychological Bulletin, 118, 55-107.

Costello, E. J., Angold, A., Burns, B. J., Stangl, D. K., Tweed, D. L., Erkanli, A., et al. (1996). The Great Smoky Mountains Study of Youth. Goals, design, methods, and the prevalence of DSM-III-R disorders. Archives of General Psychiatry, 53, 1129-1136.

Craske, M. G. (2003). Origins of phobias and anxiety disorders: Why more women than men? London: Elsevier.

Crick, N. R., \& Zahn-Waxler, C. (2003). The development of psychopathology in females and males: Current prog- perspective, we may not be optimally equipped by nature for a novel environment of millions of people living in close proximity and near complete anonymity, given that our inherited emotional and social predispositions prepared us for life in small, stable, cooperative communities of extended kin. To the extent that individuals are able to create such communities within the wider ecological framework of their urban existence they may be expected to live healthier lives. ress and future challenges. Development and Psychopathology, 15, 719-742.

Curry, J. F., March, J. S., \& Hervey, A. S. (2004). Comorbidity of childhood and adolescent anxiety disorders. In T. H. Ollendick \& J. S. March (Eds.), Phobic and anxiety disorders in children and adolescents: A clinician's guide to effective psychosocial and pharmacological interventions. Oxford: Oxford University Press.

Daniels, D., \& Plomin, R. (1985). Origins of individual differences in infant shyness. Developmental Psychology, $21,118-121$.

DuPont, R. L., Rice, D. P., Miller, L. S., Shiraki, S. S., Rowland, C. R., \& Harwood, H. J. (1996). Economic costs of anxiety disorders. Anxiety, 2, 167-172.

Emde, R. N., Plomin, R., Robinson, J., Campos, J., Corley, R., DeFries, J., et al. (1992). Temperament, emotion, and cognition at 14 months: The MacArthur Longitudinal Twin Study. Child Development, 63, 1437-1455.

Erickson, M., Egeland, B., \& Sroufe, L. A. (1985). The relationship between quality of attachment and behavior problems in preschool in a high risk sample. Monographs of the Society for Research in Child Development, 50(No. 209), 147-186.

Ferdinand, R. F., Van Lang, N. D., Ormel, J., \& Verhulst, F. C. (2006). No distinctions between different types of anxiety symptoms in pre-adolescents from the general population. Journal of Anxiety Disorders, 20, 207-221.

Finch, A. J., Lipovsky, J. A., \& Casat, C. D. (1989). Anxiety and depression in children and adolescents: Negative affectivity or separate constructs. In P. C. Kendall \& D. Watson (Eds.), Anxiety and depression: Distinctive and overlapping features. San Diego, CA: Academic Press.

Foote, D., \& Seibert, S. (March, 1999). The age of anxiety: Do male and female brains respond differently to severe emotional stress? In a flurry of new research, scientists are finding tantalizing clues. Newsweek.

Geary, D. C. (1998). Male, female: The evolution of human sex differences. Washington, DC: American Psychological Association.

Goldstein, D. B. (2009). Common genetic variation and human traits. New England Journal of Medicine, 360, 1696-1698.

Gosling, S. D., \& John, O. P. (1999). Personality dimensions in nonhuman animals: A cross-species review. Current Directions in Psychological Science, 8, 69-75.

Hummelen, B., Wilberg, T., Pedersen, G., \& Karterud, S. (2007). The relationship between avoidant personality disorder and social phobia. Comprehensive Psychiatry, 48, 348-356. 
Izard, C. E. (1991). The psychology of emotions. New York: Plenum Press.

Jackson, E. D., Payne, J. D., Nadel, L., \& Jacobs, W. J. (2005). Stress differentially modulates fear conditioning in healthy men and women. Biological Psychiatry, $59,516-522$.

Jensen, P. S., \& Hoagwood, K. (1997). The book of names: DSM-IV in context. Development and Psychopathology, 9, 231-249.

Joyce, P. R., Rogers, G. R., Miller, A. L., Mulder, R. T., Luty, S. E., \& Kennedy, M. A. (2003). Polymorphisms of $D R D 4$ and $D R D 3$ and risk of avoidant and obsessive personality traits and disorders. Psychiatry Research, $119,1-10$

Kessler, R. C., Berglund, P., Demler, O., Jin, R., Koretz, D., Merikangas, K. R., et al. (2003). The epidemiology of major depressive disorder: results from the National Comorbidity Survey Replication (NCS-R). Journal of the American Medical Association, 289, 3095-3105.

Kessler, R. C., Berglund, P. A., Demler, O., Jin, R., \& Walters, E. E. (2005). Lifetime prevalence and age-of-onset distributions of $D S M-I V$ disorders in the National Comorbidity Survey Replication (NCS-R). Archives of General Psychiatry, 62, 593-602.

Kessler, R. C., Chiu, W. T., Demler O., \& Walters, E. E. (2005). Prevalence, severity, and comorbidity of twelve-month $D S M-I V$ disorders in the National Comorbidity Survey Replication (NCS-R). Archives of General Psychiatry, 62, 617-627.

Kessler, R. C., McGonagle, K. A., Zhao, S., Nelson, C. B. Hughes, M., Eshleman, S., et al. (1994). Lifetime and 12-month prevalence of $D S M$-III- $R$ psychiatric disorders in the United States: Results from the National Comorbidity Survey. Archives of General Psychiatry, 51, 8-19.

Klein, R. G., \& Pine, D. S. (2002). Anxiety disorders. In M. Rutter \& E. Taylor (Eds.), Child and adolescent psychology (4th ed.). Oxford: Blackwell Science

Kraft, P., \& Hunter, D. J. (2009). Genetic risk predictionAre we there yet? New England Journal of Medicine, $360,1701-1703$.

LaFreniere, P. J. (2000). Emotional development: A biosocial perspective. Belmont, CA: Wadsworth.

LaFreniere, P. J. (2005). Human emotions as multipurpose adaptations: An evolutionary perspective on the development of fear. In R. Burgess \& K. MacDonald (Eds.), Evolutionary perspectives on human development. Thousand Oaks, CA: Sage.

LaFreniere, P. J., \& Dumas, J. E. (1992). A transactional analysis of early childhood anxiety and social withdrawal. Developmental and Psychopathology, 4, 385-402.

LaFreniere, P. J., Masataka, N., Butovskaya, M., Chen, Q., Dessen, M. A., Atwanger, K., et al. (2002). Cross-cultural analysis of social competence and behavior problems in preschoolers. Early Education and Development, 13, 201-219.

LaFreniere, P. J., \& Sroufe, L. A. (1985). Profiles of peer competence: Interrelations among measures, influence of social ecology, and relation to attachment history. Developmental Psychology, 21, 56-69.

Lampe, L., Slade, T., Issakidis, C., \& Andrews, G. (2003). Social phobia in the Australian National Survey of Mental Health and Well-Being (NSMHWB). Psychological Medicine, 33, 637-646.

Lazarus, R. S. (1991). Emotion and adaptation. Oxford: Oxford University Press.

Lewis, M., Feiring, C., McGuffog, C., \& Jaskir, J. (1984). Predicting psychopathology in six-year-olds from early social relations. Child Development, 55, 123-136.

Loeber, R. (1991). Questions and advances in the study of developmental pathways. In D. Cicchetti \& S. Toth (Eds.), Rochester Symposium on Developmental Psychopathology: III. Rochester, NY: Rochester University Press.

MacDonald, K. B. (1995). Evolution, the Five-Factor Model, and levels of personality. Journal of Personality 63, 525-567.

McGaugh, J. L. (2004). The amygdala modulates the consolidation of memories of emotionally arousing experiences. Annual Review of Neuroscience, 27, 1-28.

McGuire, M., \& Troisi, A. (1998). Evolutionary psychiatry. Cambridge, MA: Oxford University Press.

Nesse, R. M. (2000). Is depression an adaptation? Archives of General Psychiatry, 57, 14-20.

Nesse, R. M. (2005). Natural selection and the regulation of defenses: A signal detection analysis of the smoke detector principle. Evolution and Human Behavior, 26, 88-105.

NIMH. (2009). Social phobia (social anxiety disorder). Retrieved from http://www.nimh.nih.gov/health/publications/anxiety-disorders/social-phobia-social-anxietydisorder.shtml

Nishizawa, S., Benkelfat, C., Young, S. N., Leyton, M., Mzengeza, S., de Montigny, C., et al. (1997). Differences between males and females in rates of serotonin synthesis in the human brain. Proceedings of the $\mathrm{Na}$ tional Academy of Sciences of the United States of America, 94, 5308-5313.

Nolen-Hoeksema, S. (1998). The other end of the continuum: The costs of rumination. Psychological Inquiry, 9, 216-219.

Nolen-Hoeksema, S., \& Girgus, J. (1994). The emergence of gender differences in depression during adolescence. Psychological Bulletin, 115, 424-443.

Panksepp, J. (1998). Affective Neuroscience: The foundations of human and animal emotions. New York: Oxford University Press.

Ralevski, E., Sanislow, C. A., \& Grilo, C. M. (2005). Avoidant personality disorder and social phobia: Distinct enough to be separate disorders? Acta Psychiatrica Scandinavica, 112, 208-214.

Reich, J. (2000). The relationship of social phobia to avoidant personality disorder: A proposal to reclassify avoidant personality disorder based on clinical empirical findings. European Psychiatry, 15, 151-159.

Reich, J. (2009). Avoidant personality disorder and its relationship to social phobia. Current Psychiatry Reports, 11, 89-93.

Reichborn-Kjennerud, T., Czajkowski, N., Torgersen, S., Neale, M. C., Ørstavik, R. E., Tambs, K., et al. (2007). The relationship between avoidant personality disorder and social phobia: a population based twin study. American Journal of Psychiatry, 164, 1722-1728.

Rice, D. P., \& Miller, L. S. (1993). The economic burden of affective disorders. In R. M. Scheffler, L. F. Rossiter, \& T. W. Hu (Eds.), Advances in health economics and health services research (Vol. 14, pp. 37-53). Greenwich, CT: JAI Press.

Richters, J. E., \& Cicchetti, D. (1993). Mark Twain meets DSM-III-R: Conduct disorder, development, and the concept of harmful dysfunction. Development and Psychopathology, 5, 5-29.

Rutter, M. (2006). Genes and behavior: Nature-nurture interplay explained. Oxford: Blackwell.

Samuels, J., Eaton, W., \& Bienvenu, J. (2002). Prevalence and correlates of personality disorders in a com- 
munity sample. British Journal of Psychiatry 180, 536-542.

Shamir-Essakow, G., Ungerer, J. A., \& Rapee, R. M (2005). Attachment, behavioral inhibition, and anxiety in preschool children. Journal of Abnormal Child psychology, 33, 131-143.

Shors, T. (2002). Opposite effects of stressful experience on memory formation in males versus females. Dialogues Clinical Neuroscience, 4, 139-147.

Sroufe, L. A. (1996). Emotional development: The organization of emotional life in the early years. New York: Cambridge University Press.

Sroufe, L. A. (1997). Psychopathology as an outcome of development. Developmental and Psychopathology, 9, 251-268

Sroufe, L. A. (2007). The place of development in developmental psychopathology. In A. Masten (Ed.), Multilevel dynamics in developmental psychopathology: Pathways to the future. The Minnesota Symposia on Child Psychology (Vol. 34, pp. 285-300). Mahwah, NJ: Erlbaum.

Sroufe, L. A., Egeland, B., Carlson, E. A., \& Collins, W. A (2005). The development of the person: The Minnesota study of risk and adaptation from birth to adulthood. New York: Guilford Press.

Sroufe, L. A., Fox, N. E., \& Pancake, V. R. (1983). Attachment and dependency in developmental perspective. Child Development, 54, 1615-1627.

Suomi, S. J. (2000). A biobehavioral perspective on developmental psychopathology: excessive aggression and serotonergic dysfunction in monkeys. In A. J. Sameroff, M. Lewis, \& S. Miller (Eds.), Handbook of developmental psychopathology. New York: Springer.

Suomi, S. J. (2005). Mother-infant attachment, peer relationships, and the development of social networks in rhesus monkeys. Human Development, 48, 67-79.

Taylor, S. E. (2006). Tend and befriend: Biobehavioral bases of affiliation under stress. Current Directions in Psychological Science, 15, 273-277.
Tillfors, M., Furmark, T., Ekselius, L. \& Fredrikson, M. (2004). Social phobia and avoidant personality disorder: One spectrum disorder? Nordic Journal of Psychiatry, 58, 147-152.

Trivers, R. L. (1972). Parental investment and sexual selection. In B. Campbell (Ed.), Sexual selection and the descent of man 1871-1971. Chicago: Aldine.

Troisi, A. (2008). Psychopathology and mental illness. In C. B. Crawford \& D. Krebs (Eds.), Foundations of evolutionary psychology. New York: Taylor \& Francis.

US Census Bureau. (2005). U.S. Census Bureau population estimates by demographic characteristics. Table 2 (NCEST2004-02). Washington, DC: Author.

Wakefield, J. C. (1997). When is development disordered? Developmental psychopathology and the harmful dysfunction analysis of mental disorder. Development and Psychopathology, 9, 269-290.

Wakefield, J. C. (2005). Biological function and dysfunction. In D. M. Buss (Ed.), The handbook of evolutionary psychology. Hoboken, NJ: Wiley.

Warren, S., Huston, L., Egeland, B., \& Sroufe, L. A. (1997). Child and adolescent anxiety disorders and early attachment. Journal of American Academy of Child \& Adoles cent Psychiatry. 36, 637-644.

Weisfeld, G., \& LaFreniere, P. J. (2009). Hormones and behavior. In P. J. LaFreniere (Ed.), Adaptive origins: Evolution and human development. New York: Psychology Press/Taylor \& Francis.

Wright, R. (1994). The moral animal: The new science of evolutionary psychology. New York: Pantheon Books.

Ziabreva, I., Poeggel, G., Schnabel, R., \& Braun, K. (2003). Separation-induced receptor changes in the hippocampus and amygdala of Octodon degus: Influence of maternal vocalizations. Journal of Neuroscience, 23, $5329-5336$ 